\title{
Minha escrevivência, experiências vividas e diálogo com as mulheres indígenas do Rio Negro - Amazonas/Brasil
}

\author{
FRANCINEIA BITENCOURT FONTES \\ Universidade Federal do Rio de Janeiro, Rio de Janeiro, Rio de Janeiro, Brasil \\ hipamale@gmail.com
}

DOI 10.11606/issn.2316-9133.v29i1p179-186

\begin{abstract}
resumo Este artigo relata algumas experiências vividas como e com as mulheres indígenas, em particular as narrativas e repasse de conhecimento em forma da oralidade feitos pelas nossas avós, mães, tias e sogras, sobre o que é ser uma "mulher indígena". Pretende-se abordar os dilemas, mas também os diálogos sobre o papel político das mulheres Rionegrinas do Noroeste Amazônico. Para isso a proposta do trabalho está firmada na oralidade (narrativas), pontos de vistas dos conhecimentos e das falas das mesmas e suas interpretações; a priori ressalto a importância que devemos dar para esses "conhecimentos", o quanto as vivências dentro do mundo indígena são a ponta chave para manter essas tradições de fortalecimento e valorização destes conhecimentos. Tem sido um grande avanço mostrar o quanto as mulheres têm suas próprias teorias para explicar sua existência no mundo e suas transformações.
\end{abstract}

palavras-chave Mulheres Indígenas, conhecimentos, papel político, movimento indígena, narrativas.

Escrevivência, lived experiences and dialogues with indigenous women from Alto Rio Negro, Amazonas, Brazil

abstract In this paper, I present some lived experience as and within indigenous women. The focus is on narratives and knowledge transmitted orally by our grandmothers, mothers, aunties, and mothers-in-law about what it means to be an "indigenous woman". My intention is to explore the dilemmas in such a position, but also the political role of women from Rio Negro area, in the northeast Amazon. The proposition is based in oral narratives, point-of-view about knowledge and speeches by indigenous women and how they interpret it. It is highlighted the importance of these "knowledge" and how the experiences in the indigenous world are a key to the maintain traditions. It is a great accomplish to showcase how women have their own theories to explain the existence in this world and how it is changed.

keywords: Indigenous women. Empowerment. Political roles. Indigenous movement. Narratives. 
FONTES | Escrevivências, experiências vividas e diálogos com as mulheres indígenas | 180

\title{
Introdução
}

\author{
"Somos guerreiras, somos mulheres, e acima de tudo, capazes de \\ construir sonhos, pois somos filhas da terra, lutamos, choramos, mas \\ acima de tudo vencemos. Somos fortes e capazes".
}

(Lucicleide Kariri-Xocó)

Em minha dissertação (FONTES, 2019) fiz um estudo antropológico indígena sobre o nosso conhecimento que se dedica a compreender alguns dos mitos mais importantes que narram a criação do mundo. Naquela ocasião coloquei em destaque alguns momentos em que a mulher foi protagonista e que nos permitiriam entender como o mundo é hoje. Um dos principais objetivos foi escrever e transcrever as narrativas mitológicas baniwa da forma correta, fazendo análises e comentários de "dentro para fora" (quer dizer, falar sobre meu povo para as pessoas não indígenas), para o melhor entendimento dos seus significados. $\mathrm{E}$ neste artigo, o meu objetivo é falar do interesse e do meu olhar de entendimento sobre experiência que tive como: mulher, indígena e acadêmica, sobre as mulheres rionegrinas, na qual lutamos para dar visibilidade para nossa fala, e falar sobre o nosso papel como mulheres indígenas.

$\mathrm{Na}$ pesquisa ser mulher foi desafiador, pois certas coisas no primeiro momento pareciam tensas, mas ao longo da conversa as coisas que eu queria saber foram saindo sem precisar perguntar mais nada. Com as respostas do meu pai, eu percebia o quanto era lindo e enriquecedor ter um pai como ele, como é rico ser indígena, pois meu mundo era uma biblioteca viva e meus dicionários para explicação eram meus avós, avôs, meu pai e outros. Não estávamos aproveitando esses livros vivos. Ser mulher antropóloga e indígena é ter uma visão e ponto de vista diferente, um olhar diferenciado, pois temos um jeito de contar uma mitologia que valoriza a perspectiva e análise indígena e baniwa. A perspectiva feminina abre uma possibilidade que deve ser aprofundada em estudos posteriores. Orgulho-me de ser mulher indígena e antropóloga, falar sobre meu povo e poder daqui por diante falar na mesma linguagem com os outros antropólogos não in dígenas, pois temos a mesma formação e temos muita a ensinar a eles sobre nós mesmas.

Passei a minha infância, adolescência e a juventude na comunidade de Assunção do Rio Içana (Terra Indígena Alto Rio Negro), e sempre trabalhei na roça, ajudando meus pais, e aprendendo sobre a importância de manter viva as nossa narrativas, a forma de cuidado com o corpo, os resguardos (masculino e feminino) e outras sabedorias que são repassadas de geração em geração e o valor que significam no nosso dia a dia. A minha vida nunca foi fácil, e a sua a base sempre foram os meus pais. Tudo que faço sempre foi pensando neles, sempre quis retribuir tudo o que eles fizeram por mim.

A minha formação escolar, das séries iniciais até o ensino médio, ocorreu na comunidade, tendo professores indígenas. Eu não saí para estudar na cidade. Tudo que aprendi foi dentro de uma escola in dígena e com professores indígenas da comunidade. Isso para mim é muito gratificante e enriquecedor. Ao longo da caminhada vivi e aprendi muitas coisas, e nela eu sempre me orgulhei de fazer parte de um "entre mundos", no qual seguimos 
vivendo e compreendendo os seus significados. A minha vida foi rica em conhecimento e sabedoria transmitidos por meus pais, avós, tios, tias, primos e primas, principalmente dos meus antepassados.

Nas férias escolares íamos para o nosso sítio que fica no igarapé Uwíwa (flecha), que fica abaixo da comunidade de Assunção. Esta é uma imagem que está guardada na memória, pois no mesmo dia todas as famílias desciam com os seus aturá ou sacos de trigo com redes dentro, pois não tínhamos bolsa ou mala. ${ }^{1}$ Era uma mudança total, da comunidade para o sítio, íamos com o sorriso até as orelhas, pois era o momento mais esperado, curtir as férias, no sentido de ir para roça, comer cubiu, chupar cana, comer banana e abacaxi, assar cará e batata na roça mesmo, pular das árvores em altura de 25 a 30 metros para o rio. Íamos remando, pois naquela época não tínhamos motor rabeta, tudo era na base do braço. Remávamos seis horas em uma canoa de oito a nove metros de comprimento. Remávamos muito, pois a canoa pesava, e o meu irmão ia em uma canoinha pequena, mas era divertido, pois durante a viagem tomávamos banho, ouvíamos histórias, comíamos frutas na beira do rio. Meu pai pescava e matava todos os tipos de peixe. Meu pai é um ótimo pescador com caniço, uma vara de pescar. Hoje eu vivo em dois mundos totalmente diferentes, me adaptei a uma nova realidade, conheço meu mundo e conheço o mundo dos brancos.

Aprendi desde sempre com eles (pais, avós e tios) que temos que nos autodeterminar. Segundo André Fernando, autor baniwa, "[n]ós nos autodeterminamos como Wakoenai ou Medzeniako" (BANIWA, 2017). Sendo assim, para Juvêncio Cardoso, outro autor baniwa, "a tradução literal do termo Wakoenai é 'povos da nossa língua” ou "os falantes da nossa língua” ( wako=nossa língua, nai=povos ou coletivos) e o termo Medzeniako refere-se ao fato que "nasce falando a língua (medzeni=nascer, ako=língua)" (CARDOSO, 2018, pg. 233). Dessa forma, eu também fui aprendendo com meu pai as formas corretas de nos afirmar perante as outras sociedades.

\section{As palavras sábias dos entes queridos que já não estão mais presentes}

A memorização dos relatos ouvidos e aprendidos para se chegar na minha pesquisa de dissertação de mestrado se iniciou também por meio de pessoas que já não estavam mais presentes, mas que permanecem dentro da memória de meus entes queridos. Então, ao entardecer ouvíamos esses relatos da minha finada avó e do meu avô, eles diziam: "Na entrada da Porta do Sol Nascente, os nossos avós reuniam-se diariamente, sentavam-se em seus banquinhos, símbolos do banco da vida, passavam a cuia ou folha de ipadú ${ }^{2}$ cigarro um para outro em meio a discursos de passagem e de recebimento".

A repetição desse ritual atualizava atos criadores das divindades e da humanidade. Por meio dele, nossos avós aperfeiçoavam suas capacidades de memorização, narração de histórias de vida, superação das dificuldades e conquistas. Enquanto os homens conversam,

\footnotetext{
${ }^{1}$ Aturá é uma cesta feita com cipó titica ou wambé. Usamos a cesta para carregar mandioca, frutas e serve para carregar outras coisas também, tendo várias funções.

2 Árvore pequena da família das eritroxiláceas, da Amazônia, cujas folhas têm as mesmas propriedades da cola, de folhas elíptica, e cultivada pelos indígenas do Alto Rio Negro e outros povos.
} 
as mulheres também se sentavam no outro extremo ou na outra porta, conversando temas femininos, contando suas histórias de músicas, de trabalhos, os seus segredos femininos. No fim do ritual os homens realizavam discursos desejando bom descanso e desejando novo encontro no dia seguinte. Depois, cada um deitado na sua rede, continuava meditando sobre as realidades da vida. Pelo poder da mente esses nossos avós visitavam outras terras, outros espaços para dialogar com os seres divinos, seres da vida, das doenças, das curas etc.

Nas festas aconteciam rituais solenes relacionados aos ciclos da vida humana e da natureza, seguindo calendários específicos. Os rituais cotidianos e festivos envolvem a pessoa de corpo e coração (alma) em uma esfera especial e superior. Algumas vezes em que eu participei dos rituais baniwa tive experiências extraordinárias e indescritíveis. "Ali eu ouvi discursos enunciados pelos madzero (pajé ou benzedor) anunciando as danças e realizando discursos de passagens de cuia de ipadú e cigarro", dizia meu pai Francisco Luiz Fontes. Eu me lembro de alguns desses vários momentos: vi meu pai e outros homens tocando cariçu, com diversas melodias e ritmos, dançando acompanhados por mulheres. ${ }^{3}$ Fui envolvida e senti a defumação de proteção contra as doenças. Vi meus parentes ornamentados com plumas sagradas que passam de uma geração para outra. Admirei as pinturas faciais e corporais com seus simbolismos. Durante as danças vi homens suados, dançando, comandando ritmos com instrumentos e pés envoltos por chocalhos, cantando as músicas com línguas míticas, incompreensíveis, misteriosas e vitais.

As cantorias masculinas e femininas cantam a vida como ela é, misteriosa e vital. Entre uma parada e outra, uma boa gargalhada. Ouvem-se as vozes inconfundíveis das tonalidades dos discursos dos velhos, dos mestres de danças, das gargalhadas de nossas mães, irmãs, cunhadas, tias e avós etc. Os sons se ampliam. Após a festa, as falas, as músicas, as vozes, sons incorporam-se dentro de nós e ficamos curtindo a sonoridade interna por muitos dias.

A participação nos rituais nos leva em contato com seres muito antigos, seres divinos, mitológicos e avós sábios. A Casa Ritual proporciona nossa própria transformação, gera a vida. Vejamos a cumeeira de uma casa, lembramos do kowai, os caibros são as suas costelas. No seu ventre estamos nós. Materialmente ela é nossa contribuição para a civilização universal. Uma Casa tão simples com um grande significado. O material trabalhado é palha, madeira e chão de barro batido. O tempo pode acabar com a palha e a madeira, mas ninguém acabará com a forma de construir. Os povos possuidores de Casas Rituais olham para elas há séculos, observam a sua beleza.

\section{A nossa luta}

A partir do que apresentei, não é por acaso que muitas pessoas olham para cá, cobiçam nossas terras, criam ciúmes por nossas culturas e muitas vezes querem apropriarse de nós e de nossos saberes. É daqui que nós estamos pensando sobre nós mesmos, é daqui que temos que pensar em nós (mulheres). Nós possuímos origens diferentes, somos herdeiras de filosofias próprias aos nossos povos.

\footnotetext{
${ }^{3}$ Cariçu é uma flauta. É um instrumento musical de sopro feito de um bambu específico para este instrumento com formato de tubo.
} 
Por serem assim, nascidos da terra, os povos indígenas se relacionam com a terra como uma "mãe". A mãe cuida dos filhos desde a concepção, desde o nascimento, cuida do crescimento, cuida na vida adulta, cuida durante a velhice e quando isso acontece, ela cuida novamente, pois quando se chega ao final da vida, a pessoa volta novamente para dentro da terra, em seus cuidados. (BANIW A, 2018, s/p).

Quando se fala das mulheres indígenas dentro do contexto indígena, afirmamos que nossa relação com a terra é especial, a terra é mãe, por ser mãe, a terra é mulher, pois sustenta seus filhos, necessariamente temos que entender a mulher dentro de uma dinâmica que cria espaços políticos e ideológicos, espaços de troca de saberes, espaços de fortalecimento das identidades e das diferenças, de um espaço de negociação de interesses e de prioridades para atingir metas estabelecidas por muitos povos. Hoje, temos que pensar a especificidade dos nossos povos (nossas etnias) e pensar para todos os povos (todas as etnias).

Somos pequenas diante das coisas que acontecem nas grandes cidades e no mundo. A dita civilização chegou há muito tempo. Enquanto civilização nós precisamos dos produtos da floresta, reconhecendo o seu espaço e trabalho, pois sem a floresta a nossa vida não tem sentido. Se a destruirmos jamais ela voltará a ser o que era antes, pois as feridas se cicatrizam, mas deixam as marcas. Ensinemos aos que vem depois de nós qual é o melhor trabalho e o mais digno que existe no mundo. Não sabemos, mas sabemos que da terra brota tudo o que nós queremos como sustento, como o nosso alimento, mas também brota: o ouro, a prata, o petróleo, o ferro, água, o sal, as plantas e os animais. Nascem da terra, alguns são produtos caros e outros de pouco valores. Vamos cuidar da nossa floresta, pois ela é o melhor planeta que existe para nós. (Fala de Miquelina Tucano, na Assembleia das mulheres em Dezembro de 2014, São Gabriel da Cachoeira-AM)

Na relação entre o "nós" e o "mundo global", o mundo envolvente não-indígena, é preciso entender que nós formamos uma riqueza desse mundo: onde existe diversidade de povos, culturas, línguas, práticas culturais, saberes, conhecimentos. Existem muitos povos indígenas no Alto Rio Negro. Cada povo tem suas histórias, seus modos de organizar e viver a vida. Cada povo interage com outros povos. Por isso, entre nós em nossas práticas culturais temos muitas semelhanças. Porém, cada povo mantém sua diferença, sua identidade.

Tratando das línguas faladas podemos afirmar que uma pessoa que mora nessa região do Alto Rio Negro, fala pelo menos duas línguas diferentes. Há pessoas que falam muitas línguas. Mesmo quando alguém não consegue falar a língua de outro povo, pode compreendê-la bem. Entre as muitas línguas faladas, a língua de interação entre nós é a língua Baniwa, Koripako e Nheengatú, mas para se comunicar com outros povos, falamos a língua portuguesa. Dentro dessa leitura a figura feminina contribui muito, pois ela está 
saindo do seu povo de origem e indo se casar com homens de outros povos. Assim, ela leva sua língua e a ensina para outros povos. Vejam como é importante a figura da mulher na política linguística da nossa região do Alto Rio Negro.

Os pesquisadores nos ajudam a compreender melhor sobre os povos que moram nesta região. Eles afirmam que os habitantes destas terras pertencem a quatro famílias linguísticas: Tukano, Aruak, Maku e Yanomami. A família linguística Aruak é composta pelos povos: Baniwa, Kuripaco, Baré, Werekena e Tariana. Esses povos se espalham pela região do rio Içana, Aiari, Cuiari, Xié etc. Os Tariano habitam a região do rio Uaupés, entre Ipanoré e Periquito. Mas como outros povos estes também se espalham desde os municípios de Manaus, Barcelos, Santa Isabel do Rio Negro e São Gabriel da Cachoeira. Também se encontram na Colômbia e Venezuela. Assim é que nós somos.

\section{As políticas das mulheres}

Falar sobre as mulheres é aprofundar nossas próprias histórias étnicas, histórias da educação de cada povo e descobrir nossas raízes culturais que fundamentam a vida feminina indígena. Dentro das culturas as quais as mulheres pertencem, entre muitas etnias, as mulheres são educadas e formadas para ser o elo de ligação entre os membros da própria etnia e o dos maridos que são de outras etnias. Por ser assim, nós mulheres somos "diplomatas étnicas" pelo elo de ligação, que surge por meio de casamentos entre os clãs ou povos diferentes.

A figura feminina indígena é marcante também no processo de resistência e flexibilização das políticas indígenas. O seu compromisso com Movimento Indígena é muito importante, embora no primeiro momento não estivéssemos bem visíveis. Mas somos nós que damos a sustentabilidade ao compromisso do marido. E porque não dizer: "[e]la é mais corajosa do que os homens em muitos momentos históricos"?

Outro espaço onde a mulher assume seu compromisso importante é o campo do trabalho, desde os trabalhos caseiros até os compromissos mais amplos. Quando olhamos para a figura feminina conseguimos ver que tudo é possível fazer. A mulher indígena vai na roça, trabalha, volta carregando maniwa, rala a maniwa, faz beiju, esquenta quinhampira, faz mingau, manicoera, lava roupa, busca lenha etc. São centenas de atividades que ela realiza sem mesmo pedir recompensa.

Uma das metas que pouco a pouco vai se concretizando nas histórias das mulheres é seu aparecimento no campo da política partidária e eu acredito que nós conseguiremos ocupar os espaços, e espaços que hoje somente homens ocupam. Não é por acaso que nós hoje estudamos, lutamos e nos organizamos. Hoje, estou aqui falando por elas, levando as vozes das minhas avós e bisavós que já não estão aqui, mas seus pensamentos e falas continuam vivos, vão repassando para os nossos filhos e filhas e assim sucessivamente. Também somos nós que transmitimos conhecimentos para as crianças, pois possuímos linguagens próprias e adequadas, possuímos modos certos de transmitir conhecimentos para cada fase da vida dos nossos filhos. As avós e tias ajudam na educação. Somente com o tempo é que o pai irá ensinar aos seus filhos e filhas sobre os diversos saberes próprios de sua etnia. 
Nós que somos indígenas vamos entender muito daquilo que eu estou me referindo. Nós cuidamos da vida, cuidamos da casa, cuidamos do ambiente fora de casa, cuidamos da comunidade com outras mulheres. Somos solidárias nos trabalhos de roças, quando somos convidadas, todas participam, somos solidárias quando alguém passa necessidade. Assim como aprendi com minha mãe e avó, e nas minhas andanças vejo que em muitos momentos difíceis a última palavra é feminina.

Nesses espaços, seja na academia ou nas comunidades locais, nas cidades precisamos nos organizar nos modos de cuidar da vida, de ensinar, de superar as dificuldades. Eu vejo que elas (avós, mãe, tias, primas, cunhadas) muito pouco escrevem sobre suas práticas educativas e experiências vividas. Se nós mulheres indígenas e acadêmicas não escrevemos o que elas ou nós falamos, essas experiências vão se dissolvendo, evaporando e não sobra mais nada. Mas se estivermos bem organizadas teremos muitas forças e cuidaremos muito melhor da qualidade de ensino que será repassado aos nossos filhos.

Este diálogo sobre a participação feminina em vários momentos levou-me a perceber a coletividade que existe e que sempre existiu. Ao longo das falas e da escrita vemos as conquistas e os desafios enfrentados por nós. A tensão provocada pelo enfrentamento nas instâncias não in dígenas, possibilitou acionar o coletivo, na forma das nossas organizações, com intuito de somar forças para defender os nossos direitos. Assim, podemos continuar mantendo o nosso conhecimento, transmitindo-o sempre de forma oral ou escrita, podendo ser contado em qualquer lugar, em novos espaços ou ainda nos espaços que vamos escolher contar a nossa própria história, sendo contada por nós mesmas.

\section{Referências Bibliográficas}

CARDOSO, Juvêncio da Silva. (2018). A cuia e a formação do universo: uma abordagem baniwa no contexto da física intercultural. In: Revista do Patrimônio histórico artístico nacional, n.37. Brasília: IPHAN, pp:233-247

BANIWA, André. (2017). A Relação dos povos indígenas com a terra. In: Blog do Povo Baniwa e Koripako: Nossa presença na Web. Disponível em: https://walimanai.wordpress.com/2017/04/05/a-relacao-dos-povos-indigenas-com-aterra/ Último acesso: 06/04/2020

FONTES, Francineia Bitencourt (2019). Hiipana, Eeno Hiepolekoa: construindo um pensamento antropológico a partir da mitologia Baniwa e de suas transformações. Dissertação - Mestrado em Antropologia Social. Rio de Janeiro: PPGAS-MN/UFRJ.

TUCANO, Miquelina. (2014). Assembleia das Mulheres Indígena em São Gabriel da Cachoeira, Maloca da FOIRN. São Gabriel da Cachoeira, Dezembro de 2014.

sobre a autora
Francineia Bitencour Fontes (Fran Baniwa)

É indígena do povo Baniwa, mulher e antropóloga. Possui formação em Sociologia (licenciatura plena) pela Universidade Federal do Amazonas (UFAM), Mestrado em Antropologia Social do Museu Nacional na Universidade 
FONTES | Escrevivências, experiências vividas e diálogos com as mulheres indígenas | 186

Federal do Rio de Janeiro e é Doutoranda em Antropologia Social do Museu Nacional da Universidade Federal do Rio de Janeiro.

Recebido em 31/03/2020

Aceito para publicação em 13/05/2020 